\title{
How Facebook Connects Students’ Group Work Collaboration: A Relationship between Personal Facebook Usage and Group En-gagement
}

\author{
Praweenya Suwannatthachote, Pornsook Tantrarungroj \\ Faculty of Education, Chulalongkorn University, Bangkok, Thailand \\ Email: praweenya.s@chula.ac.th
}

Received 2012

\begin{abstract}
This study examined the relationship between the personal value of social networking technology, the frequency of Facebook use, the frequency of Facebook activities, and group engagement. The samples were 205 pre-service teachers who participated in the six-week online group project. Questionnaires were collected after the pre-service teachers submitted the project. The data were analyzed using descriptive statistics and correlation analysis to identify relations among variables. The results showed that $98 \%$ of pre-service teachers expanded their network by adding group members to their Facebook friends during the project assignment. The study found no relationship between personal purposive values of social networking technology and group engagement. Although 58.4\% of the students used Facebook many times a day, the frequency of usage was largely related to personal interests rather than being relevant to group communication and engagement with the project assignment. However, there were significant but slight correlations between the Facebook activity "view others' status to update social events" and group engagement; between "private messages" and group engagement; between "set up and share events" and group engagement; between "commenting” and group engagement; and between "clicking like" and group engagement. Therefore, educators should integrate their instructional strategy with the virtual learning environment to promote students' group engagement via social networking sites.
\end{abstract}

Keywords: Social Networking Sites (SNSs); Facebook; Group Engagement

\section{Introduction}

The most popular among the online social networking sites (SNSs) catering to a broad range of undergraduate users is "facebook.com". This website claims to have hundreds of millions of registered users. Research undertaken by the EDUCAUSE Center for Applied Research (ECAR) showed that of the 90.4\% of students in their sample population who interacted with social networking websites daily, 96.6\% indicated that they used Facebook (Smith \& Caruso, 2010). Currently, Thailand with over ten million Facebook users is ranked $16^{\text {th }}$ in the world in terms of users by country recorded by Facebook Statistics by country (March 1, 2012).

Online collaboration tools facilitate students' group work such as discussion board forum, and chat room. Formal learning management systems (LMS) such as Blackboard, Moodle, and Author are used for large classes to provide students with access to course syllabi, course documents, and course resources. In addition, each LMS provides a variety of synchronous and asynchronous communication tools. However, various kinds of SNSs such as Twitter, Facebook, and Delicious have become alternative platforms for academic use. Facebook is another informal system that fits with student modes of social interaction, and hence students have adapted it as a communication tool, as a channel to reach their friends, and as a collaborative learning tool.

Kuh (2009) emphasized two major aspects of student engagement: 1) in-class (or academic) engagement, and 2) out-ofclass engagement in educationally relevant activities. There are various factors related to engagement including investment in the academic experience at a college, involvement in co-curricular activities, and interaction with teachers and peers (Junco, 2012). In the engagement, students use physical and psychological energy, both of which are important to student success. Students who spend time and effort in in-class and out-of-class engagements are more likely to attain their desired academic outcome. The higher the level of student engagement in academic work, the greater his/her level of knowledge acquisition and cognitive growth (Pascarella \& Terenzini, 2005). Although student engagement has been researched in face-to-face environments, only the limited research undertaken by Junco (2012) and Junco, Heiberger, and Loken (2010) focused on the relationship between student engagement and social networking use.

Students use SNSs as a way to both formally and informally communicate academically topics (Greenhow \& Robelia, 2009). Other research also showed that students used Facebook for organizing collaborative classroom activities involving both online-only e.g. using Facebook as a medium for sharing notes, and online-to-offline, using the site to arrange a study group (Lampe et al., 2011). Since recent statistics have shown that today's college students use Facebook at high rates, it would be useful to measure their success in terms of usage, interaction, and user or group engagement. The latter term was defined in this study as online interaction with peers on Facebook involving group assignment activities.

The relationship between Facebook usage and group engagement has been limited by the measurements of engagement that focused on student engagement individually rather than 
group engagement. For example, Junco (2012) focused on the relationship between frequency of Facebook use, participation in Facebook activities, and student engagement. The study of Cheung, Chiu, and Lee (2011) used personal value as the key factor. They examined the relative impact of social influence, social presence, and the five key values from the uses and gratification paradigm on We-Intention on use of online social networks. Although the study did not mention group engagement directly during the classroom activities, some factors involving group activity and social engagement were found. The results showed that social presence had the strongest impact on WeIntention to use Facebook, and that group norms also had a significant influence on We-Intention to use Facebook.

This study focuses on pre-service teachers' use of Facebook as a collaborative tool in a course in Educational Technology and Information (2726207 ED TECH INFO). This course utilized a LMS and an asynchronous online discussion board for students to communicate within their groups when working on their practice assignments. In addition, students were free to use other communication tools subject to group agreement, such as SNSs, instant messaging, and e-mail. This study evaluates the relationship between the personal value of social networking technology, the frequency of Facebook use, the frequency of Facebook activities, and group engagement. The research questions used were as follows:

Question 1: Is there a relationship between the personal purposive value of social networking technology and group engagement?

Question 2: Is there a relationship between the frequency of Facebook use and group engagement?

Question 3: Is there a relationship between the frequency of Facebook activities and group engagement?

\section{Methodology}

\section{Research Settings}

This study examined the Facebook behavior of pre-service teachers who participated in online group work in 2726207 ED TECH INFO at the Faculty of Education, Chulalongkorn University, Thailand during the second semester of the 2011 academic year. This course provided pre-service teachers with knowledge and skills in the use of instructional media, information technology, and computer applications for students in schools. Participants were required to attend classroom lectures, to undertake hands-on and computer lab practice, and to complete three group projects with their team members. One of the three final class projects involved 6 weeks of online projectbased learning. For the online group project, pre-service teachers were randomly assigned to work in small groups with 4-5 members. A total of 55 small groups were created.

Blackboard's group pages were set up to provide a working space and set of communication tools that only members of the group could access. The following collaborative tools were available for students to use when participating in real-time lessons and discussions. A chat room was available for students to engage in real-time chats with group members. A file exchange facility was accessible by participants to post and share files and pertinent documents. An email facility was also provided for students to send email messages to all or selected group members. A discussion board was available for each group to conduct private discussions, with individual forums available only to those students that were part of the group.

Students were required to provide a log of their communicative interactions with peers on each group discussion board. However, students were free to use other communication tools, for example, SNSs, instant messaging, and e-mail, subject to group agreement. Six weeks after the project was assigned, students were required to complete questionnaires.

\section{Research Participants}

A total of 205 pre-service teachers agreed to participate in the study. Analysis of the demographic data for the sophomore participants revealed that $70.2 \%$ were female and $29.8 \%$ were male. Although their ages ranged from 19 to 22 years old, the majority, $71.1 \%$, were 20 years old. The students were undertaking a variety of majors, with the three most common majors being secondary education (29.3\%), primary education (17.6\%), and early childhood education (10.2\%). Other students were majoring in arts education, music education, physical education, non-formal education, and educational psychology.

\section{Instruments and Data Analyses}

The questionnaire which was used in this research was designed with closed questions. The questions were formulated based on Facebook behavior reported in education research articles (Lampe et al., 2011; Junco, 2012, Suwannatthachote, 2012). The questionnaire was divided into four main parts: 1) student demographics, 2) purposive use of social networking, 3) Facebook usage for collaborative group work with 9 items from the Likert scale, and 4) personal Facebook usage with 15 items from the Likert scale. Pre-service teachers responded to the survey after submitting their project assignment.

Descriptive statistics were conducted to determine the demographic characteristics of the participants and to analyze their use of Facebook. The data were analyzed using correlation analysis to identify relationships among variables that could help answer the research questions.

\section{Findings}

\section{Group Online Communication Tools During Project Work}

During the six-week project assignment, students were assigned to work in small groups of 4-5 students using the Blackboard course website. The Blackboard discussion board was the primary area of contact and was also where students worked collaboratively to design the storyboard for the learning object. During the first and second weeks of the six-week project period the students worked individually. From the fourth to the sixth week, the students were required to post, comment, and communicate with their peers on the group discussion board. However, students were free to use other communication tools as described previously. The results showed that students used Facebook, the Blackboard LMS group discussion board, and Windows Live Messenger (MSN) to communicate among their assigned group members (47.3\%, 35.1\%, and $18.0 \%$ respectively). The results also revealed how popular Facebook was among pre-service teachers. All participants had a Facebook account before their enrollment in this course, and during the project work they used their own preference communication tool, Facebook, to communicate among group members more than the required communication tool, the 
Blackboard LMS group discussion board. Researchers found the media attribute of Facebook is rich of communication tools in just one site such as "wall" status posts, online chat, FaceGroup (small group social networks of small group), and including alternative privacy settings. Qualitative data from the group discussion board revealed how reluctant students were to use the discussion board. Most groups asked members to opt out and use the preferred alternative communication tools instead, especially Facebook.

All students used Facebook for the collaborative work in the group project. The results showed that 98\% expanded their network by adding group members to their Facebook friends, $57.6 \%$ set up FaceGroup as an additional communication tool besides the required class communication tool, $69.8 \%$ sent personal messages via Facebook to contact group members, and 81.0\% used Facebook Chat for real time communication with group members from different majors.

\section{Group Engagement}

The data from Table 1 shows Facebook activities related to group engagement. The most three common activities were "contact other with a question related to group assignment" (Mean = 4.23 , S.D. $=0.75$ ), "come to a group consensus" (Mean $=4.17$, S.D. $=0.82$ ), and "receive information from group members" $($ Mean $=4.14$, S.D. $=0.71)$.

\section{Personal Online Communication Behavior}

Participants used different SNSs for private communication. The results showed that the top three SNSs were Facebook, Twitter, and Google Plus (100\%, 38.0\%, and 20.5\% respectively). The data indicated that all the students had Facebook accounts which they used regularly. The three highest ranking reasons for their preference of for using Facebook were to communicate among friends, associates, and family members, to be brought up to date on social events and news among groups, and to conform with their friends $(67.8 \%, 26.8 \%, 21.0 \%$ re- spectively).

\section{Frequency of Facebook Activities}

Pre-service teachers participated in a variety of Facebook activities. Among the top three activities were clicking 'Like' on others' messages, updating their status, viewing photos, and using Facebook chat (35.8\%, 35.0\%, and 33.8\% respectively). Further details are shown in Figure 1.

Table 1.

Facebook activities on group engagement.

\begin{tabular}{lcc}
\hline \multicolumn{1}{c}{ Items } & Mean & S.D. \\
\hline Receive information from group members & 4.14 & .71 \\
$\begin{array}{l}\text { Share group project information } \\
\text { (content, format, screen design technique } \\
\text { for Learning Object Storyboard) }\end{array}$ & 3.72 & .87 \\
$\begin{array}{l}\text { Discuss group assignment } \\
\text { Inquire about details of project assignment }\end{array}$ & 4.05 & .84 \\
$\begin{array}{l}\text { Schedule for group meetings } \\
\text { Share ideas and opinions }\end{array}$ & 3.71 & .75 \\
$\begin{array}{l}\text { Share knowledge and technical } \\
\text { computer tips }\end{array}$ & 3.77 & .93 \\
$\begin{array}{l}\text { Contact others with a question related to group } \\
\text { assignment }\end{array}$ & 4.23 & .75 \\
\begin{tabular}{l} 
Come to a group consensus \\
\hline
\end{tabular} & 4.39 & .98 \\
\hline
\end{tabular}

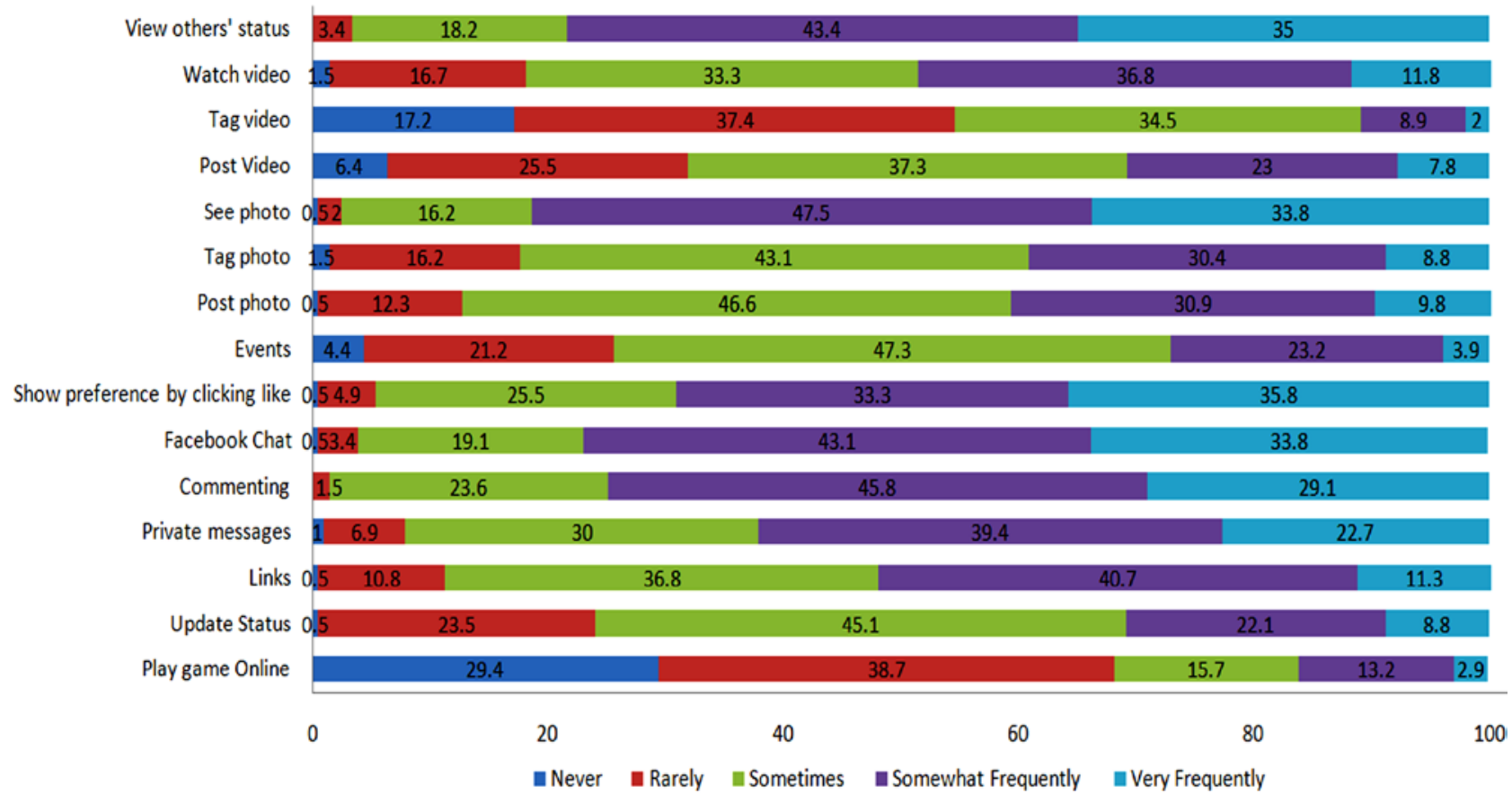


Figure 1.

Frequency of Facebook activities.

\section{Research Question 1}

To determine the answer to the first research question, Pearson correlation was used to examine the relationship between the personal purposive value of social networking technology and group engagement. The results showed that the relationship was not significantly related. However, the results did show that there were significant relationships among personal purposive value variables. Low correlations was found between "communication among friends, associates, and family members (communication)" and other values; a relationship was found between "communication" and "find new friends" (Pearson's $r=.199, p<0.01$ ), between "communication" and "update status" (Pearson's $r=.273, p<0.01$ ), between "communication" and "share information" (Pearson's $r=0.252, p<$ 0.01 ), and between "communication" and "view others' status" (Pearson's $r=.208, p<0.01$ ), and a significant but negligible correlation between "find new friends" and "update status" (Pearson's $r=.200, p<0.01$ ).

\section{Research Question 2}

The second research question sought to determine if there was a relationship between frequency of Facebook use (log on) and group engagement. The results revealed that the relationship was not significant. Most of the students spent a significant amount of time on Facebook on a daily basis. Figure 2 shows Facebook usage. Although 58.4\% of the students used Facebook many times a day, the frequency of usage was largely related to personal interest rather than being relevant to group communication and engagement with the project assignment.

\section{Research Question 3}

There were significant but low correlations between the Facebook activity "view others' status to update social events" and group engagement (Pearson's $r=0.274, p<0.01$ ), between “private messages” and group engagement (Pearson's $r=0.232$, $p<0.01$ ), between "set up and share events" and group engagement (Pearson's $r=0.218, p<0.01$ ), between "commenting” and group engagement (Pearson's $r=0.211, p<0.01$ ), and between "clicking like” and group engagement (Pearson's $r=$ 0.194, $p<0.01)$.

\section{Discussion}

Educators are introducing Facebook into the classroom for educational purposes such as promoting communication among students, increasing student collaboration, facilitating or arranging groups or meetings, and contacting another student with a question related to class. This research investigated students' usage of Facebook during the assigned group project. Pre-service teachers used Facebook in a positive way related to group engagement. The results showed a high percentage of Facebook use for collaborative work in the group project such as adding group members to their social network, using real time chat via Facebook, and sending personal messages to contact group members (98\%, 81.0\%, and 69.8\% respectively). This result is consistent with the study of Lampe et al., (2011) in that their study found students' usage of Facebook promoted the organization of collaborative classroom activities.

This study found no relationship between the personal purposive value of social networking technology and group engagement. The purposive values of using Facebook found in this study were related to individual student engagement rather than group interaction and discussion which required students' active involvement. Purposive value factors such as updating social events and news among groups, communicating among friends, associates, and family members, and expressing selfexperience and feelings with texts and pictures focused on selfattentiveness rather than contributing to group efforts. Astin (1984, cited in Junco, 2012) added that some students are more engaged than others and individual students are engaged in different activities at different levels.

There was no relationship between the frequency of Facebook use (log on) and group engagement. The data from the study of Junco (2012) showed that time spent on Facebook was negatively predictive of student engagement while Junco and Cotton (2010) found that students who spent more time chatting online had more academic impairment.

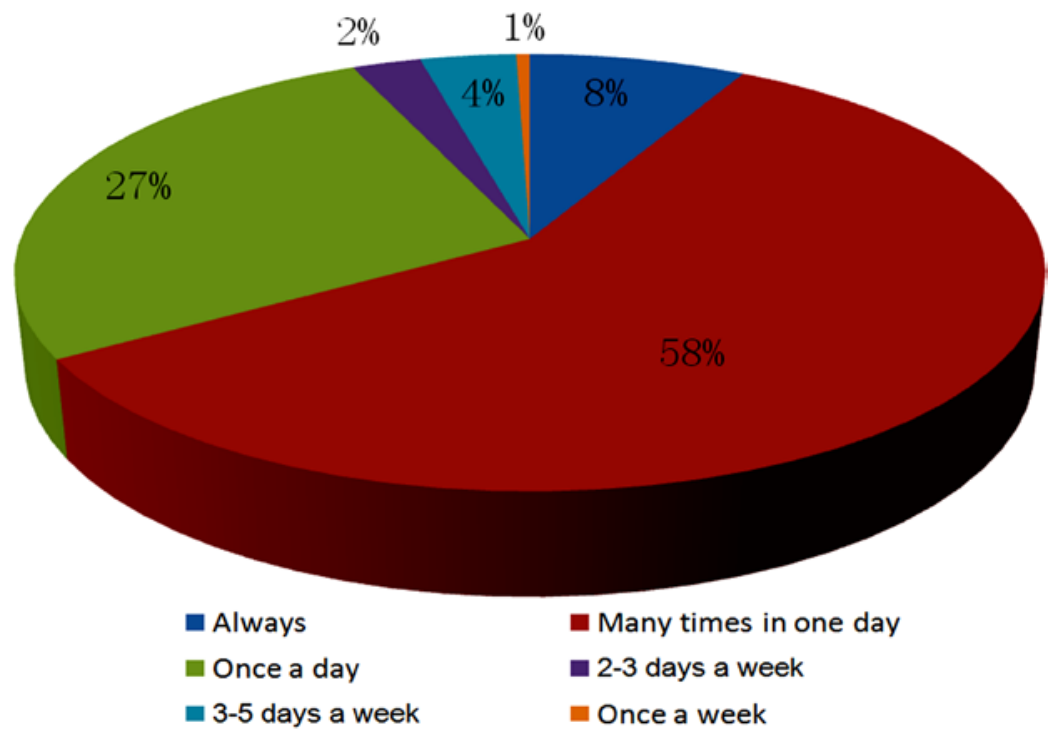


Figure 2.

Frequency of Facebook log on.

This study found that some Facebook activities, such as "view others' status to update social events”, "private messages”, "set up and share events", “commenting” and "clicking like”, had significant but slight relationships with group engagement. Therefore, educators who introduce Facebook into their classroom activities should be aware of the activities above so they can encourage more academic learning engagement. Students will communicate with friends for both academic and social discussions on Facebook. A study by Lampe et al. (2011) indicated that students perceived motivation for communicating with others when using Facebook and were likely to use Facebook for discussion of class assignments.

Further study should focus more on an instructional strategy to promote group engagement using Facebook. Educators need to put more effort into encouraging students to use Facebook for more academic purposes such as contacting others with a question relating to group assignments, sharing information on group projects, inquiring into details of project assignments, and discussing and sharing ideas and opinions.

\section{REFERENCES}

Astin, A. (1984). Student involvement: a developmental theory for higher education. Journal of College Student Personnel, 25(4), 297-308

Cheung, C. M. K., Chiu, P.Y., \& Lee, M. K.O. (2011). Online social networks: Why do students use facebook? Computers in Human Behavior. 27, 1337-1343.

Facebook statistics by country, Retrieved March 1, 2012, from http://www.socialbakers.com/facebook-statistics

Greenhow, C., \& Robelia, B. (2009). Old communication, new literacies: Social network sites as sociallearning resources. Journal of Computer-Mediated Communication, 14, 1130-1161.

Junco, R. (2012). The relationship between frequency of Facebook use, participation in Facebook activities, and student engagement. Computers \& Education. 58 (1), 162-171.

Junco, R., Heiberger, G., \& Loken, E. (2010). The effect of Twitter on college student engagement and grades. Journal of Computer Assisted Learning.27(2), 119-132.

Kuh, G.D. (2009) What student affairs professionals need to know about student engagement. Journal of College Student Development 50, 683-706.

Lampe, C., Wohn, D. Y., Vitak, J., Ellison, N. B. \& Wash, R. (2011). Student use of Facebook for organizing collaborative classroom activities. Journal of Computer-Supported Collaborative Learning. 6, 329-347.

Pascarella E.T. \& Terenzini P.T. (2005). How College Affects Students: A Third Decade of Research. Jossey-Bass, San Francisco, CA.

Facebook Statistics by Country. (March, 2012). Retrieved March 1, 2012, from http://www.socialbakers.com/facebook-statistics.

Smith, S.D., \& Caruso, J. B. (2010). Research study. ECAR study of undergraduate students and information technology, Vol. 6. Boulder, CO: EDUCAUSE Center for Applied Research, Retrieved February 29, 2012, from http://net.educause.edu/ir/library/pdf/ers1006/rs/ers1006w.pdf

Suwannatthachote, P. (2012). Exploring Pre-service Teachers' Awareness on Using Social Networking Sites: Are they ready for digital citizenship?. In T. Amiel \& B. Wilson (Eds.), Proceedings of World Conference on Educational Multimedia, Hypermedia and Telecommunications 2012 (pp. 2594-2600). Chesapeake, VA: AACE. Retrieved from http://www.editlib.org/p/41128. 